\title{
Real-Time Management and Control of a Bus Public Transport Network: The STCP Experience
}

\author{
doi:10.3991/ijoe.v5s2.1099 \\ J.F. Sousa ${ }^{1,2}$, J.R. Teixeira ${ }^{2}$ and J.B. Ferreira ${ }^{2}$ \\ ${ }^{1}$ University of Porto, Porto, Portugal \\ ${ }^{2}$ Sociedade de Transportes Colectivos do Porto, STCP S.A., Porto, Portugal
}

\begin{abstract}
STCP is the main bus operator in the Porto Metropolitan Area. The experimental phase of using fleet tracking and management systems fitted on public transport vehicles began in the late eighties, but only in 2002 the current system (SAEI) covered all the buses of the company. Nowadays, these systems are integral company management systems. In this paper, the experience of the past six years or so is presented. The main reasons for the use of such systems are detailed, the architecture and functionalities are described and the importance of accessing real-time information together with subsequent analysis of the data obtained is underlined.
\end{abstract}

Index Terms-Communication system operations and management, Public transport network, Real time systems, Road vehicle location monitoring.

\section{INTRODUCTION}

Public Transport is faced with the challenge of responding to the increasing exigency of passengers namely by providing adjusted timetables and attractive services at the same time. Real-time and accurate passenger information, improved passenger safety, better monitoring and automated management control are some of the factors that are critical for the success of transport companies $[1,2]$.

In order to improve service regularity through planning, STCP launched in 1999 an international tender for the acquisition of an Operational Control System (SAEI), providing automatic vehicle location through GPS [3] and using a TETRA mobile communication network, enabling more efficient network management and improved security for passengers and crew, and also integrating a real time information system, providing the public with information of next bus arrival times at the main stops.

It is important to have an idea of the dimension of the operation controlled by the system. STCP operates a fleet of slightly over 500 hundred vehicles, covering a network of about 540 kilometers, transporting 111 million passengers and travelling 30 million kilometers per year [4].

\section{MAIN OBJECTIVES}

Briefly, the main goals of the system were to achieve effective control of the fleet, to optimize available resources, to improve the working conditions of drivers and inspectors, to obtain more and better information about the service, to enhance the process of planning and to provide a service of better quality.
This tool replaced bus control based just on inspectors, fixed at several points of the city, who only knew what they could see or what the drivers reported on arrival to those points. Of course, all points were connected by phone to a central office but it was impossible to have an overview of the entire network that would allow making the right decision at the right time.

In fact, the new system led to a considerable improvement in service by ensuring safe and punctual bus operations, further enhanced by the passenger information functions offered by the system.

The system can also be used to control bus destination and information displays as well as to trigger both audio and visual announcements. This enhances the quality of passenger information.

Coordinated connections increase convenience for passengers. The system monitors bus movement permitting the bus dispatchers to give the appropriate instructions to the bus drivers.

A fully integrated CCTV monitoring ensures problemfree surveillance of any events in the buses by control centres. This provides a significant improvement in passenger security without needing additional staff.

In short, the modern operation control systems for public transport set the standard for the centralized control of bus operations in terms of enhancing cost effectiveness, optimization of timetables and services, and for high level of passenger safety [5].

\section{ARCHITECTURE}

The four components of the system (Fig. 1) are the mobile communication network, the onboard equipment, the dispatch centre and the information system. All these subsystems work to provide the necessary data to the controller.

The mobile communication network is based on TETRA, a digital communication system that allows voice and data in the same channel.

The onboard equipment is the responsible for determining the location of the vehicle, the communication with the dispatch centre, the multimedia passenger information, and the ticketing integration. The main equipment is the onboard computer and the TETRA radio. All the necessary data for the system's work are resident in the onboard computer and are loaded at the beginning of the service. This reduces the quantity of data flowing through the communication network.

The dispatch centre (Fig. 2) incorporates the heart of the system, a master computer that receives all the 
information from the other subsystems and has a resident database with all the parameterization, while also storing all data for future use. Linked directly by a LAN Ethernet at $100 \mathrm{Mbit} / \mathrm{s}$ there are eight dispatch workstations, one configuration and statistics workstation and one video wall (Figs. 3 and 4). Additionally, as a support for the activity of the controller, there are video signals from the streets provided by the town-hall equipments (Fig. 5).

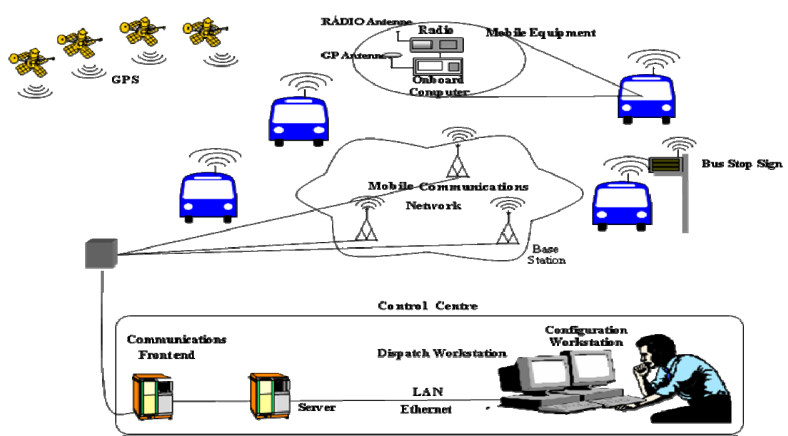

Figure 1. Architecture of the SAEI [6]

The information system displays are located onboard and at some stops and allow the passengers to receive information of the next stop, the waiting time for the next bus and the visual and sound information sent by the company.

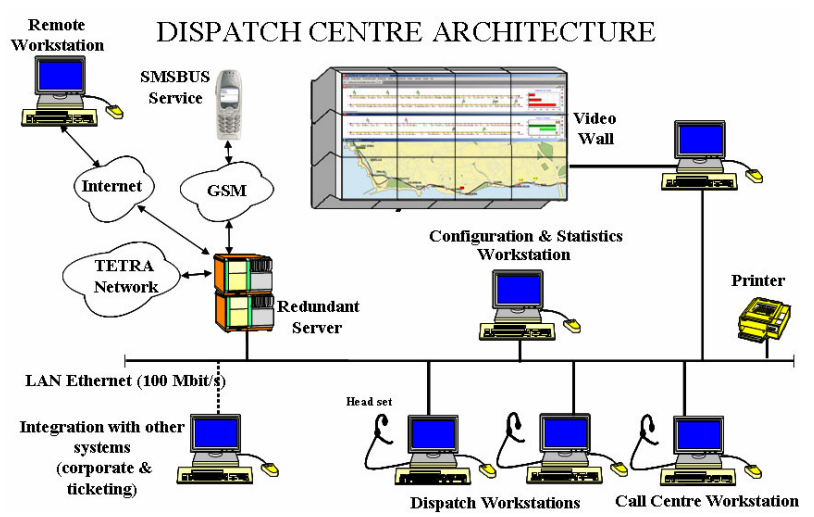

Figure 2. Architecture of the Dispatch Centre [6].

\section{FEATURES}

The SAEI system provides a complete range of control, management and regulation functions for passenger information and services and enables integration with other existing systems in the company $[7,8]$.

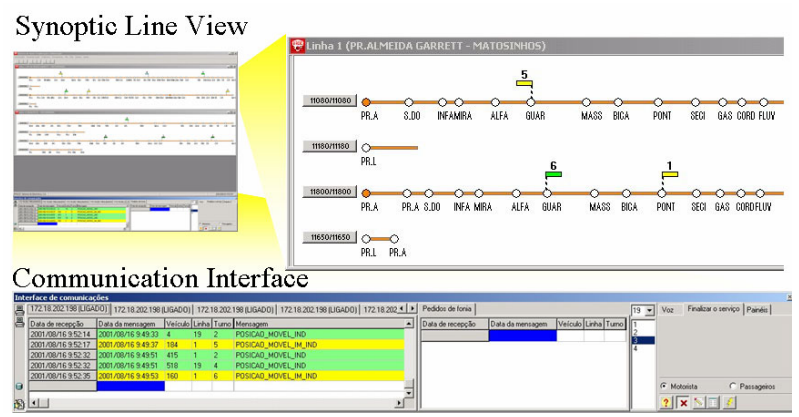

Figure 3. Examples of display screens in the dispatch workstations

\section{Electronic Map View}
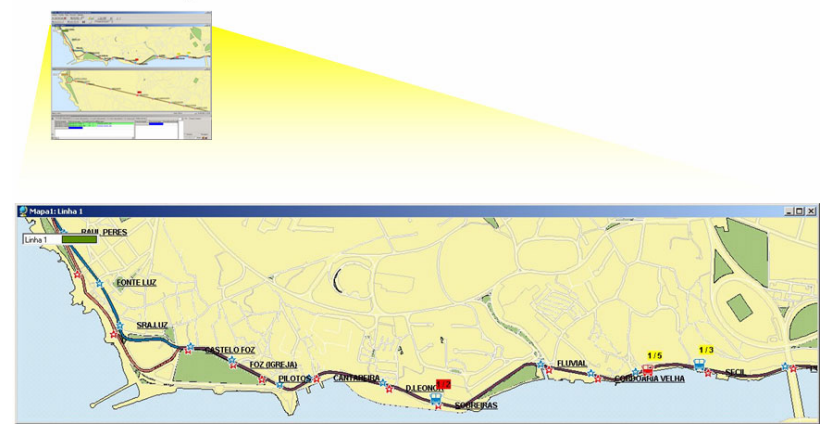

Figure 4. Examples of display screens in the dispatch workstations

The real-time fleet management allows actions such as improving the distribution of passengers by bus, reducing the waiting time for customers at bus stops, minimizing the loss of travels, preventing buses from running too close together in time and adjusting the supply of service in response to unforeseen occurrences.

The messaging service, both for drivers and passengers, the configuration and historical record of operation data, the regulation in the control centre and onboard, the hidden emergency alarm (with recording of image and sound environment, audible in the dispatch centre), the passenger information inside and outside the bus, the counting of incoming and outgoing customers at each stop, and the back-office management of the occurrences and complaints are just some other features of the system.

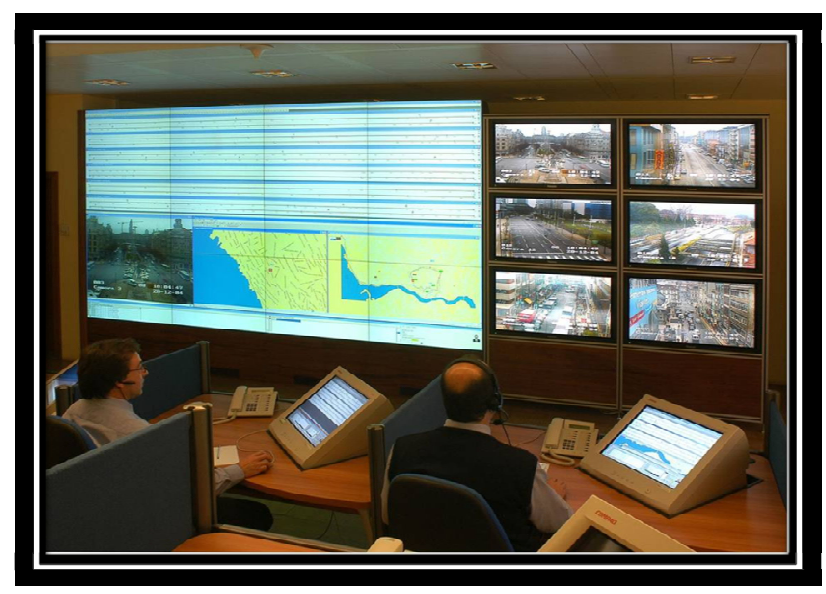

Figure 5. Workstations and video wall in the Dispatch Centre

Another important additional feature is the information given to the clients through mobile phone - the next buses passing at a stop or, for a specific line, which will be the passing time for the next buses - obtained by means of an algorithm developed on the basis of data like the location of the bus and its speed during a certain time period preceding the call. During 2008, the average of daily calls in weekdays was 3000 . This information can also be given to blind clients through specific software developed for mobile phones. Moreover, this feature allows a blind client to know the time he will have to wait for the bus of a particular line, warn him when the bus is due to arrive in 1 minute while also informing the driver that a blind client is waiting for the bus at that stop. 


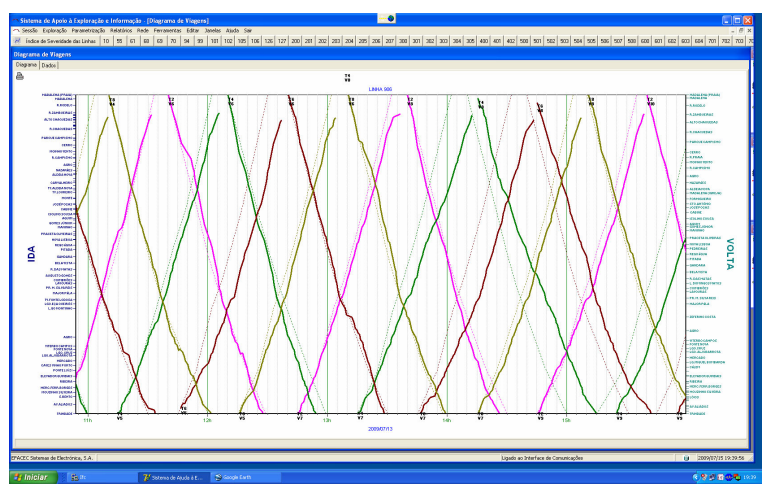

Figure 6. Graphical comparison between planned and real trip times

\section{CONCLUSION}

Reliability of public transport systems is one of the major concerns for both passengers and public transport companies. The technological evolution that has occurred in the last decades made available to companies the use of intelligent transport systems which promote the improvement of their services, namely in terms of schedule reliability, in order to increase clients' satisfaction and to decrease damage caused by successive schedule deviations.

The case study described in this paper is the six-year experience of an Operational Control System (SAEI) at STCP. The SAEI at STCP provides real-time management and control of its bus public transport network, and is integrated with a passenger information system. It still gives the additional possibility of adapting diverse systems that provide added-value. In this way, through this system, several developments were made, guaranteeing adaptation to current and future projects.

In fact, the system stores, for instance, large amounts of information about the trips. This information can be used in later analyses, making possible the identification of planning errors and behaviour patterns, which can be used to supply a better service in the future (Fig. 6).

The SAEI also supplies data management systems for analyzing services, passengers and fares, allowing comparative graphs with historical files, among many other possibilities [9].

The recent integration of the SAEI with the new ticketing system can be used to illustrate the previous statements.

The use of contactless tickets and the requirement to validate tickets on all journeys became compulsory on the $1^{\text {st }}$ January 2007, following the expansion of the contactless ticket system to all vehicles of the public service. All the bases had been put in place alongside the SAEI to ensure an accurate assessment of the degree of compliance of the service provided and more efficient management of production resources, allowing them to be adapted to the effective mobility requirements of customers.

Most of the alterations made to supply during the second half of 2007 resulted from the information obtained from this new information system, a fact that proves the gains achieved with this new tool.

\section{REFERENCES}

[1] A. Goel, Fleet Telematics: Real-time management and planning of commercial vehicle operations. Springer, Operations Research / Computer Science Interfaces Series, vol. 40, 2008.

[2] M. Mazzon, "Fleet Management Experiences in Italy," in EuroChina Intelligent Transport Systems Workshop, April 2002.

[3] S. Murphy, "How to choose a GPS fleet management system: what features are right for you?," Management Quarterly, vol. 45, June 2004.

[4] STCP, S.A., Report and Accounts 2008, Editor: STCP, SA, 2009.

[5] Funkwerk IT, "Integration and Concentration: Operations control systems for railway main lines and public transport," in www.funkwerk-it.com, 2009.

[6] EFACEC, Sistemas de Electrónica S.A., "STCP: Fleet Management and Public Information System (SAEI)," Technical Report from the Transport Systems Unit, 2007.

[7] T. G. Dias, J. P. Sousa, and J.F. Cunha, "Genetic algorithms for the bus driver scheduling problem: a case study," Journal of the Operational Research Society, vol.53, pp. 324-335, 2002. (doi:10.1057/palgrave.jors.2601312)

[8] J. M. Moreira, C. Soares, A. M. Jorge, and J. F. Sousa, "The effect of varying parameters and focusing on bus travel time prediction," in 13th Pacific-Asia Conference on Knowledge Discovery and Data Mining, vol. LNAI 5476, Springer, 2009, pp. 689-696.

[9] V. Zeimpekis, C. D. Tarantilis, G. M. Giaglis, and I. Minis, Dynamic Fleet Management: Concepts, Systems, Algorithms \& Case Studies. Springer. Operations Research / Computer Science Interfaces Series, vol. 39, 2007.

\section{AUTHORS}

J. F. Sousa is with Faculdade de Engenharia, Universidade do Porto and with STCP, S. A., Porto, Portugal (e-mail: jorgefreire@stcp.pt).

J. R. Teixeira is with STCP, S. A., Porto, Portugal (email: rteixeira@stcp.pt).

J. B. Ferreira is with STCP, S. A., Porto, Portugal (email: jferreira@stcp.pt).

This article was modified from a presentation at the IRF'2009 conference in Porto, Portugal, July 2009. Submitted 12 October 2009. Published as resubmitted by the authors on 20 October 2009. 